\title{
Deceptive love and denied endings: tropes in the music of Billy Joel
}

\author{
SEAN ATKINSON \\ Texas Christian University, Fort Worth, TX, USA \\ E-mail:sean.atkinson@tcu.edu
}

\begin{abstract}
The music of Billy Joel is long overdue for prolonged attention from the scholarly field. As Walter Everett has acknowledged (2000), Joel's music is often more in line with common-practice systems than with popular genres, and when combined with his intuitive understanding of numerous popular styles, makes for a rich trove of harmonic interest. One of the common-practice devices Joel utilises effectively is the evaded cadence (also called a deceptive motion). His use of this harmonic motion reveals two tropes in his music: Deceptive Love describes the complicated nature of love in 'She's Got a Way' and 'She's Always a Woman', while Denied Ending describes the unfinished and unresolved quality at the end of 'Miami 2017'. Uncovering these tropes in Joel's songs leads to a better understanding of the lyrics and the harmonic progressions that underlie them.
\end{abstract}

The music of Billy Joel is ripe for scholarly attention, as evidenced by several recent critical manuscripts that focus on Joel's music rather than his turbulent personal life, and a recent public musicology conference dedicated to his work. ${ }^{1}$ Indeed, much can be said about Joel's use of harmonic events and how those events influence our interpretation of the lyrics. Walter Everett touched on this idea when he described Joel's use of harmony as often more in line with the common practice than with popular genres. For example in the song 'James', Joel uses a 'more learned and conservative' style in the song, while 'Laura' features a tonal landscape more common to a pop-rock song (Everett 2000). Joel's mastery of learned techniques, combined with an intuitive understanding of standard pop-rock paradigms, creates a rich trove of much harmonic interest.

One learned harmonic event that Joel uses with great care is the evaded cadence. ${ }^{2}$ Evaded cadential motions in tonal music have the power not only to extend phrases, but also to engender meaning. Song is particularly effective at creating meaning, with the lyrics offering another perspective on the harmonic event taking place. The combination of evaded cadences with the lyrics allows for tropes to emerge that change the meaning of the song in dramatic ways. This article explores

1 'It's Still Rock and Roll to Me': The Music and Lyrics of Billy Joel, A Public Musicology Conference took place in October 2016 at Colorado College in Colorado Springs, Colorado, USA.

2 I say 'with great care' because the three songs under discussion here are the only ones of Joel's songs that I am aware of that make prominent use of evaded cadences. There are plenty of V-vi harmonic motions, but not all of them are deceptive and none of them rise to the same level of prominence as these do. 
the connection between deceptive harmonic motion and the lyrics, and examines the resulting tropes in three Billy Joel songs. 'She's Got a Way', the first track on Joel's debut album Cold Spring Harbor, ${ }^{3}$ and 'She's Always a Woman', from The Stranger, are essentially love songs in which Joel tries to explain what it is he loves about 'her' and, in the latter, to defend a woman he loves; the deceptive motions featured throughout complicate the meaning and interpretation of the song. And in 'Miami 2017', Joel provides an apocalyptic vision of 1970s New York City, with a final unresolved deceptive motion that leaves listeners to ponder the inconclusive ending.

\section{Deceptive motion and dramatic effect}

Before delving into an analysis of the use of deceptive motions in these songs, it is pertinent to review the concept of deceptive motion and its function in tonal music. In his study of Schubert, Edward T. Cone describes the effect of evaded, or what he calls promissory, cadences: 'The combination of emphasis [on the evaded chord] and separation [from the intended chord of resolution] draws special attention to the unresolved chord and enables it to establish its influence so powerfully that it seems to require later attention' (Cone 1982). If a cadence is evaded, a promise is made by the music to come back later to 'fix' the cadence and see that it is appropriately resolved. The intervening music, then, becomes marked and unique from the music around it. Its function is now to correct the previous harmonic 'error' rather than to contribute to the larger harmonic trajectory of the piece. It is parenthetical to the music around it, with its function separated and somewhat unconnected. Janet Schmalfeldt more specifically engages with the music that follows a deceptive event: 'at the very point where the cadential tonic should be gained, the composer will "back up" - either to the beginning of the phrase, or simply to its cadential idea - and repeat this unit, or repeat a variant of it, in order to approach the cadence "one more time"" (Schmalfeldt 1992). Schmaldfeldt further describes the dramatic effect of these events, writing that evaded cadences and the subsequent 'one more time' repetition 'not only dramatise the eventual cadence but also yield an expansive and exhilarating ... phrase' (Schmalfeldt 1992). William Caplin also acknowledges the dramatic potential of evaded cadences, writing that 'the lack of any event representing formal closure, combined with the breaking off of a highly goal-directed process just before its completion, arouses a powerful expectation for further cadential action' (Caplin 1998). An evaded cadence generates a powerful potential that can only be discharged by the arrival of the expected, promised, and structurally required cadence. The tension between those two events is located in Schmaldfeldt's 'one more time' music.

Cone, Schmaldfeldt and Caplin all refer to these moments as evaded cadences, but they are also commonly referred to as deceptive motions or even deceptive cadences. I hesitate to use the term deceptive cadence in these instances since the term cadence implies closure of some kind. The events described in these songs are clearly not closing ideas. Instead, they create a need to hear more and a requirement for the music to continue. The term deceptive motion, rather, captures both the lack of

\footnotetext{
${ }^{3}$ While this is the initial release of the song, the more popular and well-known version is a live recording released a decade later. The analysis of this song that follows is based on the live version, although the differences between the versions are discussed later in the article.
} 
closure and the dramatic qualities associated with it. Indeed, the dramatic qualities of these events are directly connected to the amount of musical time used during the 'one more time' section of a phrase. To that end, Schmaldfeldt examines multiple evaded cadential scenarios: those that simply repeat the local cadential formula, those that repeat the entire preceding phrase and those that repeat more than the phrase. In terms of effect on the song, a quick turnaround of just the cadential material is likely to have less dramatic effect than a section that repeats the entire phrase or more. These longer repetitions further separate the music from the surrounding material since, after all, the phrase could have easily ended at the moment of the deceptive motion. Instead, the music is allowed to spin out, and the more music that is involved, the higher the dramatic impact is. In the Billy Joel songs examined here, each handles the 'one more time' section differently, and therefore each has a different dramatic effect on the song.

\section{Tropes}

According to Robert Hatten, tropes arise from the juxtaposition of contradictory or previously unrelated types (Hatten 1994), and can emerge in many different ways. In Hatten's study of the music of Beethoven, he shows that the tropes emerge from the blending of unrelated Classical topics. In the middle of the finale of Beethoven's ninth symphony, for example, a march begins that would normally signify a high-style topic associated with royalty and the upper class. However, Beethoven includes with the march high-pitched metallic percussion, a sign of a non-Western other that lowers the discourse of the march. The combination of these unrelated types results in a trope, the so-called Turkish march that aligns the finale's message of spirit and brotherhood not with royalty, but with all humankind.

Classical topics have long played an important role in the analysis and interpretation of music. Many scholars have used these topics and their manipulations to describe a host of meaningful insights in music, beginning perhaps with Leonard Ratner (1985). Kofi Agawu (1991 and 2009) explores the use of Classical topics in both Classical- and Romantic-era music, Raymond Monelle (2000 and 2006) acknowledges the role that Ratner played in cataloguing the topics and further refines their definition, and Hatten (1994 and 2004) identifies the way in which topics interact in Classical music to create tropes. All of these studies demonstrate that, at a fundamental level, meaning is created through opposition, and the juxtaposition of disparate Classical topics in a single piece of music creates opportunities to make interpretations of meaning.

In popular song, the domains of music and text can have a similar ability to create meaningful tropes. A deviation or unusual development in one type (or domain) causes the juxtaposed other to become marked, and therefore forces the listener to reinterpret the moment. Markedness is a concept used by Hatten to help define the appearance and meaning of tropes, and is borrowed from linguistic studies as a way to explain the way in which binary oppositions can specify and create meaning. However, these moments must 'transcend correlation and provoke an emergent interpretation' (Hatten 1994). In other words, a deceptive motion might just be a deceptive motion, with no larger interpretative bias. It is when that deceptive motion aligns with something prominent in the lyrics that a trope emerges, elevating the pairing of music and lyrics to a new interpretative place. Everett explores such binary 
oppositions and markedness pairs, as well as other aspects of meaning, in a study of post-millennial rock (Everett 2012). At the end of that article, Everett posits the question, 'Does the naïve listener possess the competence to make such nuanced decisions?' In other words, would an untrained ear understand the topical play in the above Beethoven example, or in any of the tropes that appear in Joel's music? He ultimately agrees with numerous scholars on the subject that yes, 'the normal and fully competent appreciation of tonal events is one held even by those blissfully ignorant of the techniques that underlie them' (Everett 2012). Indeed, most lay listeners will certainly understand the setup for an authentic cadence (having heard it their entire lives) and the surprise that comes from the denial of that event, causing the music to become marked in comparison with the music around it.

The songs by Joel discussed here create tropes by means of deceptive motions in lyrically significant locations. The same basic deceptive event occurs in the two love songs ('She's Got a Way' and 'She's Always a Woman'): the music reaches a point of expected closure, moves deceptively, turns around to try again (Schmalfeldt's 'one more time' technique), and returns to the expected harmonic resolution. It is the 'one more time' (hereafter OMT) music that helps create the trope. While the OMT section is structurally necessary in order to bring the phrase to a harmonic close, it is nonetheless a marked departure from the music around it, especially since the deceptive motion is a staple of every verse in both songs rather than a onetime event. The combination between being musically necessary while also being a repeated feature of the song itself is what gives these OMT sections such weight.

Think of this juxtaposition in another way. 'She's Got a Way' features a harmonic move to ${ }^{b} \mathrm{VI}^{7}$ (E-flat major seventh), which extends the phrase by an extra measure before returning to tonic. The expectation is for a cadence at that moment, but a cadential arrival at this point would no longer allow for the word 'anyway'. The presence of the OMT measure, then, stands apart from the rest of the phrase metrically and forces us to consider the presence of the word 'anyway' at that exact moment in the song.

Finally, the overall dramatic effect of the trope is largely dependent on how much work the music must do to achieve a satisfactory harmonic closure. As described above, the longer it takes the music to turn around and achieve the promised cadence, the more dramatic the effect. In the case of popular song, a longer turnaround also affords more words to become associated with the deceptive motion and the OMT section that follows. However, the continuum of increased length equating with more drama is far from linear, as we will see in 'Miami 2017', where the deceptive motion that ends the song is never corrected, arguably leading to a much stronger dramatic effect.

\section{Deceptive Love: 'She's Got a Way' and 'She's Always a Woman'}

The texture of 'She's Got a Way' is simple, featuring only the piano and Joel's singing, causing Thomas MacFarlane to describe it as a 'stately and emotionally direct ballad' (MacFarlane 2016). Indeed, this love song about an unknown woman is striking in its reverence and simplicity. The lyrics refer to a woman for whom Joel cares deeply, although he can't seem to fully articulate the reasons why. The last lines of each verse are shown below, with words in italics indicating the use of the deceptive motion and the OMT section: 
But there doesn't have to be a reason anyway

But it lifts me up when we are walkin' anywhere

A million dreams of love surround her ev'rywhere

But I know that I can't live without her anyway

In this case, the quick one-measure turnaround only encompasses the final word in each verse. This same harmonic progression is used three more times throughout the song. In each case, the antecedent phrase ends with a half cadence and sets up the expectation of a consequent phrase ending with an authentic cadence. The deceptive motion to bVI is quickly corrected by simply stepping up through bVII and back to tonic. Of particular note here, in addition to the deceptive motion, is the move to ${ }^{b} \mathrm{VI}^{7}$ rather than the more common minor submediant heard in typical V-vi deceptive motions. This briefly invokes the minor mode at the end of the phrase, further strengthened by the use of bVII and, combining with the deception itself, uniquely marks the end of the phrase. It also adds a touch of melancholy to the song.

This marked moment of deceptive motion has caught the attention of many listeners. In Fred Schruers' biography of Joel, he writes, 'The last word hangs in the air, completing the thought but also trailing off, disrupting the tempo and seemingly giving in to the emotion, to the state somewhere between heart and hormones sometimes known as being in love with love' (Schruers 2014). MacFarlane describes this moment not by the deceptive motion, but by the ascending bVI ${ }^{7}-b \mathrm{VII}-\mathrm{I}$ progression that follows. 'Billy Joel succeeds [in making this song unique], primarily through the use of a remarkable series of ascending chords that appear during the concluding cadence of each verse' (MacFarlane 2016). Indeed, this is a striking moment in the song and adds further insight into the song's lyrics.

Returning to the lyrics, we can now consider the italicized words in the context of the deceptive motion and the return to tonic that follows. While there doesn't have to be a reason 'anyway', he knows and we know there is actually something, and it is much more important than this lyric would suggest at face value. She may lift him up when they are walking 'anywhere', but we know the location matters. A million dreams of love surround her 'everywhere', but his dreams, in his space, are what truly matters. These moments point to a trope I call Deceptive Love, in which the face value of the lyrics about love become complicated by the use of the deceptive motion, calling them into question

Deceptive Love is also heard in 'She's Always a Woman', although it features a different deceptive motion and longer OMT section. This song is lyrically complicated, as the words seem to describe a woman who is cutthroat, no nonsense and 'nobody's fool', yet Joel ends each verse saying 'she's always a woman to me'. Joel is highlighting the duality of his then wife and manager, and this attempt to describe her was met with confusion by many listeners. Joshua Duchan writes, 'Written for Elizabeth Weber, who was known for her tough negotiation skills that could be perceived as unfeminine, Joel's lyrics defend her. They explain that he loves all facets of her personality, even those that might strike others as unlovable' (Duchan 2017). Joel received some negative response to this song, with many people mistaking the lyrics, thinking he was a misogynist and hated women. Yet the song always returns to a message of love and admiration. In fact, the deceptive motions and OMT sections help to reinforce this aspect of the song.

The deceptive motion occurs on the word 'see', as the harmony moves from dominant to the major mediant (V to III). This motion is different from the deceptive 
move in 'She's Got a Way', in that it arrives on a more distantly related harmony. The mediant can often act as a tonic substitute in a progression, just as the submediant does in a typical V-vi deceptive motion. However, the arrival of a chromatically altered tonic substitute along with a strong expectation of tonic arrival creates a particularly effective deceptive motion. The major mediant, as a distantly related harmony to the home key, also requires more musical effort during the OMT section to turn around back to tonic. This leads to an additional four measures of music and an additional two lines of lyrics.

Other writers and critics have tended to focus exclusively on the lyrics of this song, noting the harsh tone with which Joel describes Weber, contrasted with the love and devotion he feels towards her anyway. Everett, like Duchan, takes care to highlight that Joel is defending the woman in question. Specifically, Everett points to the line, 'blame it all on yourself 'cause she's always a woman to me' as evidence that others think she is one thing, but Joel is defending her as his beloved (Everett 2000). That line is one of several that become marked by correlation within the OMT sections of the song, giving that line and the others that come to the defence of Weber further emphasis and prominence. It is also important to note that the refrain 'she's always a woman to me' is only heard in the context of the OMT section:

And she only reveals what she wants you to see

She hides like a child but she's always a woman to me

And she'll take what you give her as long as it's free

Yeah, she steals like a thief but she's always a woman to me

The trope in this song serves two purposes. As described above, it draws attention to an important lyrical moment, but it also plays into the notion of duality. Joel wanted to paint a true picture of the woman he loved, and doing so required describing the qualities that other people saw most often. A deceptive harmonic motion is also a moment of duality. In some way, it achieves resolution by attaining the tonic scale degree, but at the same time requires further action to fully resolve the progression.

Both 'She's Got a Way' and 'She's Always a Woman' are love songs that speak about the nature of specific relationships, as well as Joel's views on women in general. Duchan describes in great detail the latter, using the lyrics of 'She's Always a Woman' and many of Joel's other songs to show his reverence of strong women: 'Joel's songs about strong (and dangerous and baffling) women reveal a deeper power dynamic in which the men are not clearly the superior or, in many cases, are clearly inferior' (Duchan 2017). The use of deceptive motion in these two songs bolsters the underlying theme of love. The trope of Deceptive Love describes this duality well, combining the musical deceptive motion with the lyrical description of complicated love. In 'She's Got a Way', Deceptive Love describes that je ne sais quoi that Joel cannot fully articulate: love as mysterious and intangible. In 'She's Always a Woman', Deceptive Love depicts the complicated and unresolved nature of Joel's relationship with Weber. Love as complicated and multi-faceted.

\section{Denied Ending: 'Miami 2017'}

'Miami 2017' is one of Joel's more popular songs (and naturally a highlight of his live shows in 2017). The song was written in 1975, a turbulent year in New York City 
caused by an economic downturn and the inability of the city to make good on debts without immediate federal assistance. When that assistance failed to materialise, many feared the worst for the city. 'Miami 2017' is written from the perspective of someone living in 2017 who remembers the destruction of the city 40 years earlier. Thankfully the city escaped from the financial crisis and avoided the doomsday scenarios described in the lyrics, but this song remains one of Joel's most beloved songs.

The ending of the song suggests that the final phrase will conclude as all of the previous verses had done. However, the concluding harmonic move is deceptive, moving from IV to bVI. ${ }^{4}$ Unlike the motion to bVI in 'She's Got a Way' and to III in 'She's Always a Woman', this deceptive motion is never corrected. No OMT section exists to 'fix' it; it simply ends, hanging on the bVI with no sense of closure. ${ }^{5}$ Previous writers on Joel's music have, to my knowledge, not acknowledged this strange and unresolved ending, but it pairs nicely with the song's lyrical content. The final verse returns to the slow, reflective nature of the song's opening and ends on the line, 'to keep the memory alive'. The lyrical memory, of course, is of New York, but with the music's end on the deceptive motion, it too remains alive, having never achieved closure. Joel's song evokes a trope of Denied Ending, the notion that musical time may have ended, but the song continues forward, in some sense, indefinitely.

Songs that end deceptively with no return to tonic are exceedingly rare, but there is at least one other instance of it in Billy Joel's musical output. The studio recording of 'She's Got a Way' also ends with motion to bVI and is never corrected. The more popular recording of the song (the version referenced earlier) is from a live recording released on a collection of live songs in 1981.6 This is the version that most people know, as it was subsequently released on various greatest hits collections and recently on an album entitled Love Songs. The original studio version, with its unresolved conclusion, exhibits both tropes of Deceptive Love and Denied Ending. MacFarlane attributes this odd harmonic ending to the song's placement as first on the album, with the unresolved motion acting as an invitation to listen to the rest of the album (MacFarlane 2016). Denied Ending lends this song a new interpretive light, extending the mysterious and intangible aspects of Deceptive Love indefinitely, just as the story of the destruction of New York remains an open question at the end of 'Miami 2017'.

${ }^{4}$ IV in this case acting as a substitute for V at the expected cadence (a IV-I cadence as opposed to a V-I cadence). This fairly common progression in pop-rock has its roots in blues, and David Temperley discusses it at length, even referencing another Billy Joel song ('Just the Way You Are'). In that article, Temperley does describe a deceptive IV, in which IV replaces an expected tonic arrival, but that deceptive move is quite different from the deceptive motions being discussed here (Temperley 2011).

5 Although the arrival of 'VI is the culmination of the song's harmonic trajectory, it is not quite the end of the song. After this moment, the song returns to a dream-like piano figure that began the track, featuring arpeggiated triads and florid melodic turns, eventually leading to a fade-out.

${ }^{6}$ When Joel performs 'Miami 2017' live, he changes the ending and arrives on the tonic after the concluding piano gesture. Where studio versions allow for deceptive endings, live performances seemingly do not. The one exception I have found to this is in The Rolling Stones' 'Heart of Stone'. In addition to the numerous deceptive motions in the chorus, this song also ends deceptively and fades out. The Stones, however, conclude on the vi harmony when this song is performed live, as heard in a 2002 concert at Palais Royale in Toronto. See https://www.youtube.com/watch?v=Ot6yc4cqfJA (last accessed 6 June 2018). 


\section{Conclusion}

Joel is certainly not the only songwriter to use deceptive motion in song. Many songs, spanning a timeframe from the 1960s through today, use deceptive motion to some extent. 'Cry Baby' by Garnet Mimms (1963) is a great example, as the deceptive move from $\mathrm{V}$ to vi at the conclusion of every chorus leaves the song feeling unsettled, while all the while the lyrics describe a man waiting for a former lover to return after a breakup with another man. 'Crying in the Rain' by the Everly Brothers (1962) and 'Heart of Stone' by The Rolling Stones (1964) similarly end every chorus with a deceptive motion. What sets these apart from Joel's use of deceptive motion, however, is the lyrical content at those moments of deception. Where Joel varies the lyrics associated with each deceptive event, adding to the meaning of the deceptive event, these songs repeat the same words each time (in the case of the latter two songs, the lyrics at deceptive moments are the titles of the songs). Accordingly, the troping effect of these moments is diminished.

The song 'I Will' (1968) by The Beatles features two deceptive motions in the coda. The song's lyrics describe a singer who, much like Joel's protagonist in 'She's Got a Way', is unsure of the reasons why he loves this person. When the song first moves to the coda, a deceptive harmonic motion from $\mathrm{V}$ to vi begins a fourmeasure OMT section that extends the phrase and allows for the line 'For the things you do endear you to me. And you know I will.' However, when the expected moment of harmonic resolution (the correction to the previous deceptive motion) arrives on the words 'I will', the song moves deceptively yet again to bVI. This harmony is held for two measures before tonic is finally achieved, once again on the words 'I will', but this time leaping up an octave. Two factors contribute to this moment as the Deceptive Love trope. First, the song is about love, especially a mysterious and unexplainable love. Second, the deceptive motion actively participates in the lyrical description of love. Although the singer quite clearly loves this ineffable woman, perhaps the deceptive motion softens his resolve and sews just the tiniest hint of doubt.

The use of deceptive motions in love songs is not something relegated to the past, however. Although more of an 'after-the-love' song, Ben Folds's 'Gone' (2001) describes a person still dealing with a romantic breakup one year after the fact. The lyrics begin, 'I thought I'd write, I thought I'd let you know/That the year since you've been gone I've finally let you go'. After further describing the hardships he endured, the bridge includes the only deceptive motion on the line 'The chemicals are wearing off'. At face value, this suggests that he no longer needs to dull the pain of their breakup, but when coupled with the deceptive motion, perhaps he still can't 'consider you gone' as the final lyrics state. So not Deceptive Love in this case, but perhaps Self Deception or Self Denial?

I should reiterate that the mere correlation between lyrical and musical events does not create a trope. Take for example the ending of The Beatles' 'With a Little Help From my Friends' (1967). The song ends with a similar deceptive formula heard in 'She's Got a Way', concluding with a penultimate move to $\mathrm{kVI}$, yet there is no larger trope present. This is because the song ends on the word 'friends', and this word is anything but novel or unique. In 'She's Got a Way', the words featured during the deceptive motion hold significant weight and provide additional lyrical context. However, at this point in 'With a Little Help from My Friends' we've heard 'friend' many times, each accompanied by the expected घVII-IV-I cadential 
motion. Here, in the final moments of the song, a brief appearance of $\bullet \mathrm{VI}$ certainly delays the ending, but no emergent meaning is made manifest. If anything, this moment could be read as ironic: the literal high note achieved on the deceptive harmony could reference the lyric's repeated suggestions to get 'high with a little help from my friends'.

Harmonic events that become marked as result of deceptive motion force us to reconsider the lyrics in those moments. This is true in the songs by Billy Joel, but also true of any song. Whether the music is marked by deceptive motion or any other event, the combination of music and lyrics at that moment creates tropes that bring a deeper or alternate reading of the song. The tropes of Deceptive Love and Denied Ending are but two of an array of tropes possible in popular music. As shown in the studio recording of 'She's Got a Way', tropes can interact with each other. Joel's skill at songwriting provides an ideal corpus of material upon which to identify more tropes and therefore tools to help uncover meaning in popular music.

\section{References}

Agawu, K. 1991. Playing With Signs: A Semiotic Interpretation of Classical Music (Princeton, NJ, Princeton University Press)

Agawu, K. 2009. Music as Discourse: Semiotic Adventures in Romantic Music (New York, Oxford University Press)

Caplin, W. 1998. Classical Form: A Theory of Formal Functions for the Instrumental Music of Haydn, Mozart, and Beethoven (Oxford, Oxford University Press)

Cone, E. T. 1982. 'Schubert's promissory note: An exercise in musical hermeneutics', $19^{\text {th }}$-Century Music, 5/3, pp. $233-41$

Duchan, J. S. 2017. Billy Joel: America's Piano Man (Lanham, MD, Rowman and Littlefield)

Everett, W. 2000. 'The learned vs. the vernacular in the songs of Billy Joel', College Music Symposium, 18/4, pp. 105-29

Everett, W. 2012. 'The representation of meaning in post-millennial rock'. Analysen Populärer Musik, pp. 149-69

Hatten, R. 1994. Musical Meaning in Beethoven (Bloomington, IN, Indiana University Press)

Hatten, R. 2004. Interpreting Musical Gestures, Topics and Tropes: Mozart, Beethoven, and Schubert (Bloomington, IN, Indiana University Press)

MacFarlane, T. 2016. Experiencing Billy Joel: A Listener's Companion (Lanham, MD, Rowman and Littlefield)

Monelle, R. 2000. The Sense of Music: Semiotic Essays (Princeton, NJ, Princeton University Press)

Monelle, R. 2006. The Musical Topic: Hunt, Military, and Pastoral (Bloomington, IN, Indiana University Press)

Ratner, L. 1985. Classic Music: Expression, Style, Form (New York, MacMillan Publishing Company)

Schmalfeldt, J. 1992. 'Cadential processes: the evaded cadence and the "one more time" technique', Journal of Musicological Research, 12, pp. 1-52

Schruers, F. 2014. Billy Joel: The Definitive Biography (New York, Three Rivers Press)

Temperley, D. 2011. 'The cadential IV in rock', Music Theory Online, 17/1

7 Thank you to the anonymous reader who made this observation. 